\title{
Kabak ve Patlıcan Dilimlerinin Kuruma Davranışının Deneysel İncelenmesi
}

\author{
Muhammed Safa KAMER ${ }^{1}$, Hüseyin Emre ŞAHİN ${ }^{1}$, Kerim SÖNMEZ ${ }^{1}$, Muharrem IMAL ${ }^{1}$, Ahmet KAYA $^{1 *}$ \\ ${ }^{1}$ Kahramanmaraş Sütçü İmam Üniversitesi, Makine Mühendisliği Bölümü, Kahramanmaraş, Türkiye
}

\begin{abstract}
ÖZET: Bu çalışmada, aynı boyutta kesilen kabak ve patlıcan dilimlerinin kuruma davranışları deneysel olarak incelenmiştir. Deneyler üç farklı hız $(0.5,1.0$ ve $1.5 \mathrm{~m} / \mathrm{s})$ ve üç farklı sıcaklıkta $\left(40,50\right.$, ve $\left.60{ }^{\circ} \mathrm{C}\right)$ konvektif bir kurutucuda yapılmıştır. Elde edilen kuruma eğrileri, literatürde yaygın olarak kullanılan modellerden Lewis, Henderson-Pabis ve iki terimli eksponansiyel modllerine yerleştirilmiştir. Kabak ve patlıcan dilimlerinin kuruma karakteristiklerini tanımlamada iki-terimli eksponansiyel ve Henderson-Pabis modellerinin uygun olduğu belirlenmiştir. Ayrıca difüzyon $D_{\text {eff }}$ ve kütle taşınım hm katsayılarının kurutma havası sıcaklığı ve hızıyla değişimleri incelenmiştir. Artan hız ve sıcaklıkla kütle transfer parametrelerinin arttığı ve kuruma süresinin azaldığı tespit edilmiştir.
\end{abstract}

Anahtar Kelimeler: Kabak, Patlıcan, Kuruma Kinetiği, Kurutma Modelleri, Difüzyon Katsayısı, Kütle Taşınım Katsayıs

\section{Experimental Investigation of Drying Kinetics of Pumpkin and Eggplant Slices}

\begin{abstract}
In this study, behaviour of zucchini and eggplant slices has been investigated as experimantally. Experiments have been made in a convective dryer at three different drying air velocity $(\mathrm{U}=0.5 \mathrm{~m} / \mathrm{s}, 1.0 \mathrm{~m} / \mathrm{s}$ and 1.5 $\mathrm{m} / \mathrm{s}$ ) and at three different drying air temperatures $\left(40,50\right.$, and $\left.60{ }^{\circ} \mathrm{C}\right)$. The experimental moisture data were fitted to Lewis, Henderson-Pabis and two-term exponential models which are widely used in the literature. The two-term exponential and Henderson - Pabis models were found to describe the drying characteristics of zucchini and eggplant slices better. The variations of diffusion $D_{\text {eff }}$ and mass transfer coefficients $h m$ with the drying air temperature and drying air velocity have been investifated. The mass transfer parameters were increased and drying time was decreased with increasing velocity and temperature.
\end{abstract}

Keywords: Pumpkin, Eggplant, Drying Kinetics, Drying Models, Diffusion Coefficient, Mass Transfer Coefficien

\section{GíRiş}

Ülkemizde çok çeşitli meyve ve sebze üretimi yapılmaktadır. Bunlardan biri olan patlıcanın insan beslenmesinde önemli bir yeri vardır. Patlıcanın 100 gramında, 24 kalori bulunmakta ve bu bitkide; protein, yağ, karbonhidrat ve A, B1, B2, C vitaminlerini de içermektedir [1]. Ayrıca ülkemiz patlıcan üretiminde dünyada ilk beş ülke arasında yer almaktadır [1]. Sebze grubu içerisinde yer alan, içerdiği vitamin ve mineraller bakımından insan beslenmesinde büyük önem taşıyan, ekonomik önemi yüksek olan kabak ise dünyada en çok yetiştirilen sebze türlerini içerisinde bulunduran kabakgiller grubu içerisinde bulunmaktadır [2].

Birçok ülkede, sezon sebze ve meyvelerini işletme imkanı yetersiz olduğundan, ürünler kısa sürede bozulup atılmakta ve büyük ölçüde ekonomik kayba uğranmaktadır [3]. Bunu önlemek için sezon meyvelerinin bir şekilde dayanım ömürlerinin artırılması gerekmektedir. Bu amaçla; konserveleme, dondurma ve kurutma işlemleri yapılmaktadır. Gıda ürünlerinde vitamin değerlerinin korunması, görüntüsünün bozulmaması, tadın muhafazası, azalan kütle ile paketleme, depolama ve nakliye imkanları bakımından; kurutma, en uygun prosestir [4,5]. Kurutma işlemi iki faktöre bağlıdır. Bunlar; iç (ürün nemi, yoğunluğu, gözenekliliği v.s.) ve dış (kurutma havası hızı, sıcaklığ1 ve bağıl nemi) faktörlerdir. Literatürde yapılan çalışmaların çoğu diş faktörlerin, ürünlerin kuruma davranışlarına olan etkisini araştırmak üzerinedir. Literatürde, g1da ürünlerinin kuruma davranışını araştıran birçok çalışma mevcuttur. Kaya v.d. elma dilimlerinin kuruma davranışını deneysel olarak araştırmışlardır [6]. Bu çalışmada farklı sıcaklık, hız ve bağıl nem parametrelerini göz önüne almışlardır. Henderson ve Pabis modeli, Newton modeli ve iki-terim exponsiyel modelleri incelenerek, bu modellerin deneysel çalışmaya benzer sonuçlar verdiğini tespit etmişlerdir. Kouchakzadeh ve Shafeei mikrodalga konvektif kurutucuda İran fistığının kuruma davranışı incelemişlerdir [7]. Doymaz ve Gol farklı kalınlıklardaki patlıcan dilimlerinin kuruma davranışına sıcaklığın etkisini deneysel araştırmışlardır [8]. Doymaz armut dilimlerinin konvektif kurutucuda kurutulmasını deneysel olarak çalışmıştır [9]. Bu çalışma öncesinde 
sitrik asit ve sıcak su ile ön işlem yapmış, sitrik asitle yapılan kurutma çalışmaların daha kısa sürede tamamlandığını görmüşlerdir. Ortiz v.d. sarımsak dilimlerinin konvektif kurutucuda farklı sicaklık değerlerinde yaptıkları çalışmalarda ürünün nem içeriğini, fiziksel ve kimyasal özelliklerindeki değişimleri araştırmışlardır [10]. Purkayastha vd. bir konvektif kurutucuda domates dilimlerinin kuruma davranşına sıcaklık ve hızın etkisini araştırmışlardır [11]. Ayrica elde edilen veriler farklı kurutma modellerine yerleştirilmiş ve en uygun modelin Henderson-Pabis modeli olduğunu görmüşlerdir. An vd. Çin zencefilinin kuruma davranışını, farklı kurutma metodlarında incelemiş ve bunların ürün üzerindeki etkisini araştırmışlardır [12]. Tao vd. dutun kuruma davranışını konvektif kurutucuda incelemişlerdir [13]. Rahman vd. Güneydoğu Asya egzotik meyvesi rambutanın kuruma davranaşının deneysel olarak incelemiş ve elde edilen sonuçları matematiksel modellerde karşılaştırmışlardır [14]. Adiletta vd. üzümün kuruma davranışına sıcaklığın etkisini araştırmış ve en uygun sıcaklığın $50^{\circ} \mathrm{C}$ olduğunu belirlemişlerdir [15]. Khawas vd. muz dilimlerinin kuruma davranışını farklı sıcaklıklarda deneysel olarak araştırmışlardır [16].

$\mathrm{Bu}$ çalışmada, tasarlanarak imal edilen bir konvektif kurutucuda kabak ve patlıcan dilimlerinin kuruma davranışı ve kütle transfer parametrelerine (difüzyon ve kütle taşınım) kurutma havası sıcaklığı ve hızının etkisi araştırılmıștır.

\section{MATERYAL VE YÖNTEM}

\subsection{Malzeme}

Yaklaşık aynı büyüklükte olan ve aynı cinsteki kabak ve patlıcanlar yerel bir marketten alınarak $4{ }^{\circ} \mathrm{C}$ sıcaklığa sahip soğutucuda saklanmıştır. Kurutma işlemi için kabak ve patlıcanlar, dilim kalınlığı $1 \mathrm{~cm}$ olacak şekilde kesilerek hassas terazi üzerine yerleştirilmiştir. Önce kabak dilimleri sonra da patlıcan dilimleri için deneyler yapılmıştır. Konvektif kurutucu her deney öncesinde 30 dakika kadar çalıştırılarak dengeye gelmesi sağlanmış ve sonrasında ölçümlere başlanmıştır. Yapılan her bir deney için her 30 dakikada bir ölçüm alınmış ve doğrudan bilgisayara kaydedilmiştir. Kabağın ve patlıcanın ilk nem içeriği, KERN marka (DBS 60-3 model) nem tayin cihazıyla belirlenmiştir.

\subsection{Deney Düzeneği}

Çalışmada kullanılan konvektif kurutucunun şematik gösterimi Şekil 1'de verilmiştir. Deney düzeneği, hızı kontrol edilebilir fan, 1sıtıcı, hava giriş damperi, hava çıkış damperi ve taze hava ile kullanılmış havanın belirli oranda karıştırıldığı karışım odacığı, test bölgesi, hassas terazi, sıcaklık ve nem ölçerler, akış düzenleyici, veri okuma ve kaydetme sistemi ile bilgisayardan oluşmaktadır. Isı yalıtımı iyi bir şekilde yapılan konvektif kurutucuda, proses boyunca test bölgesinde kurutma havası hızı ve sicaklığı sabit tutulmaktadır. $\mathrm{Bu}$ amaçla konvektif kurutucuda hız ve sıcaklık kontrol üniteleri kullanılmıştır.

Test bölgesinde, akışı bozmayacak şekilde yerleştirilmiş ve sızdırmazlığı iyi bir şekilde sağlanmış olan hassas terazi bulunmaktadır. Test bölgesi içindeki hız, bağıl nem ve sıcaklık değişimleri ile hassas terazideki anlık kütle değişimleri, belirlenen periyotlarda, bir yazılım programı aracılığıyla doğrudan bilgisayara kaydedilebilmektedir. Ayrıca bu değerler konvektif kurutucu üzerinde bulunan PLC ekranı ile de takip edilebilmektedir.

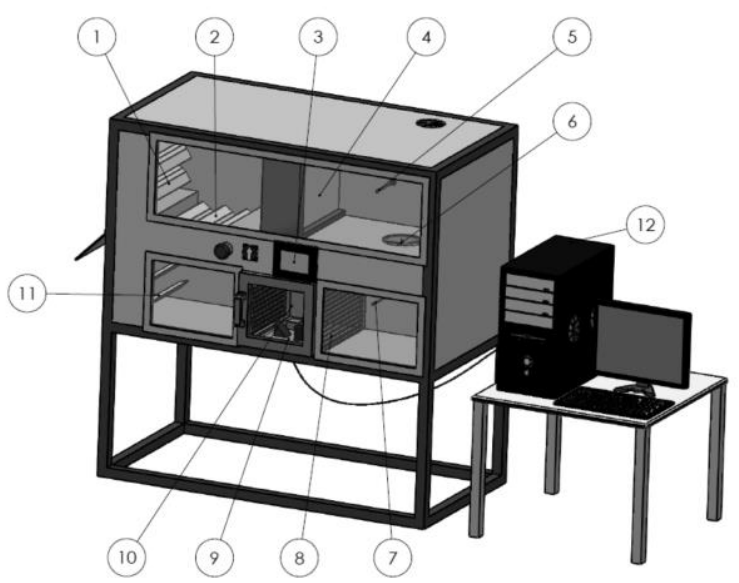

1) Taze hava damperi, 2) Karışım damperi, 3) PLC okuyucu, 4) Isıtıc1, 5-7) Sicaklık ve Nem ölçerler ve hız sensörü, 6) Fan, 8) Akış düzenleyici, 9) Hassas terazi, 10) Test bölgesi, 11) Egzoz damperi, 12) Bilgisayar

Şekil 1. Deneyde kullanılan konvektif kurutucu

Konvektif kurutucu üzerinde bulunan PLC ekranında, test bölgesi içindeki istenilen hız ve sıcaklık değerleri girilmekte ve kurutma süresi boyunca bu değerler sabit tutulmaktadır. Beş farklı bölgeye yerleştirilen hız, sıcaklık ve bağıl nem sensörleri ile kurutma işlemi takip edilebilmekte, değerler istenen periyotlarda bilgisayara doğrudan kaydedilebilmekte ve PLC ekranından da görülebilmektedir.

Kurutma işlemine başlamadan önce, sistem yaklaşık 30 dakika kadar çalıştırılarak sistemin dengeye gelmesi sağlanmıştır. Kabağın ilk nem içeriği \% 92.437 y.m. (12.222 kg H $2 \mathrm{O} / \mathrm{kg} \mathrm{k.m.),} \mathrm{patlıcanın} \mathrm{ilk} \mathrm{nem} \mathrm{içeriği}$ ise \% 92.431 y.m. $\left(12.212 \mathrm{~kg} \mathrm{H} \mathrm{H}_{2} \mathrm{O} / \mathrm{kg} \mathrm{k.m}\right.$.) olarak belirlenmiştir. Deneyler, kabak ve patlıcan için ayrı ayrı olcak şekilde, üç farklı kurutma havası hızında $(0.5 \mathrm{~m} / \mathrm{s}$, $1.0 \mathrm{~m} / \mathrm{s}$ ve $1.5 \mathrm{~m} / \mathrm{s})$ ve üç farklı sicaklıkta $(40,50$ ve 60 $\left.{ }^{\circ} \mathrm{C}\right)$ gerçekleştirilmiştir. Kurutma işlemi, üründe kütle değişimi olmayıncaya kadar devam etmiştir (verilen sıcaklıkta denge nem değeri). Her deney en az üç kez tekrarlanarak ortalama değerler alınmıștır. Kabak 
deneyleri için her deneyde hassas teraziye $300 \mathrm{~g}$ ağırlığında, $1 \mathrm{~cm}$ kalınlığındaki kabak dilimleri konulmuştur. Patlican deneyleri için de yine her deneyde hassas teraziye $300 \mathrm{~g}$ ağırlığında, $1 \mathrm{~cm}$ kalınlığındaki patlıcan dilimleri konulmuştur.

\subsection{Kurutma Ĕgrilerinin Matematiksel Modellere Uyarlanması}

Boyutsuz nem oranı aşağıdaki şekilde tanımlanmıştır.

$$
M R=\frac{M-M_{e}}{M_{i}-M_{e}}
$$

Burada $M$ zamanla değişen ürün nem içeriği, $M_{i}$ ilk nem içeriğgi, $M_{e}$ ürünün verilen sıcaklıktaki denge nem içeriğidir (kurutma sonundaki nem içeriği). Tablo 1 'de verilen üç farklı ince tabakalı kurutma modeli, $1 \mathrm{~cm}$ kalınlığında dilim şeklinde kesilen kabak ve patlıcanın kuruma davranışını tanımlamada kullanılmıştır.

Tablo 1. Kurutma modelleri

\begin{tabular}{|c|c|c|}
\hline Model ismi & Denklem & Referans \\
\hline Lewis & $M R=\exp (-k t)$ & Lewis [17] \\
\hline $\begin{array}{l}\text { Henderson- } \\
\text { Pabis }\end{array}$ & $M R=a \exp (-k t)$ & $\begin{array}{l}\text { Henderson } \\
\text { ve Pabis [18] }\end{array}$ \\
\hline $\begin{array}{l}\text { İki-terimli } \\
\text { eksponansiyel }\end{array}$ & $\begin{array}{l}M R=a \exp \left(-k_{0} t\right)+ \\
b \exp \left(-k_{1} t\right)\end{array}$ & $\begin{array}{l}\text { Sharaf-Eldeen } \\
\text { vd. [19] }\end{array}$ \\
\hline
\end{tabular}

$\mathrm{MR}$, nem oranı; $\mathrm{a}, \mathrm{b}$ kurutma katsayıları; $\mathrm{k}, \mathrm{k}_{0}$ ve $\mathrm{k}_{1}$ kurutma sabitleri; t, kurutma süresi

Deneysel verilerden faydalanarak kurutma katsayıları ile difüzyon ve kütle taşınım katsayılarını elde etmede bir bilgisayar programı olan Sigma Plot kullanılmıştır. Elde edilen değerlerin kullanılabilirliğini sorgulamada korelasyon katsayıs $\mathrm{R}^{2}$ ve tahmini standart hata (SEE) önemli kriterlerdir [20,21].

Korelasyon katsayısı $\mathrm{R}^{2}$;

$$
R^{2}=\frac{S S R}{S S T}=1-\frac{S S E}{S S T}
$$

Tahmini standart hata (SEE);

$S E E=\sqrt{\frac{\sum_{i=1}^{N}\left(M R_{\text {deneysel }, i}-M R_{\text {hesaplanan }, i}\right)^{2}}{N}}$

\subsubsection{Difüzyon Katsayısının Belirlenmesi}

Kurutmada önemli parametrelerden biri olan difüzyon katsayısı, kabak ve patlıcan dilimleri için farklı hız ve sıcaklıklarda hesaplanmıştır. Hesaplamada Fick difüzyon denklemi kullanılmıştır. Difüzyon katsayısının sabit, ilk nem içeriğinin homojen olduğu dilim şeklinde kesilen kabak ve patlıcan için bu denklem Crank tarafından aşağıdaki gibi elde edilmiştir [22].

$M R=\frac{M-M_{e}}{M_{i}-M_{e}}=\frac{8}{\pi^{2}} \sum_{n=0}^{\infty} \frac{1}{(2 n+1)^{2}} \exp \left(-\frac{(2 n+1)^{2} \pi^{2} D_{e f f} t}{4 L^{2}}\right)$

Burada $D_{\text {eff }}$ difüzyon katsayısı $\left(\mathrm{m}^{2} / \mathrm{s}\right)$, L kurutulan ürünün yarı kalınlığı, $\mathrm{t}$ kurutma süresidir. $\mathrm{Bu}$ denklem serinin ilk terimi alınarak basitleştirilebilir [8];

$$
M R=\frac{M-M_{e}}{M_{i}-M_{e}}=\frac{8}{\pi^{2}} \sum_{n=0}^{\infty} \exp \left(-\frac{\pi^{2} D_{e f f} t}{4 L^{2}}\right)
$$

(5) numaralı denkleme SigmaPlot programinda regresyon analizi uygulanarak difüzyon katsayısı elde edilmiştir.

\subsubsection{Kütle Taşınım Katsayısının Belirlenmesi}

Yüzeyden transfer edilen kütle miktarı kütle taşınım katsayısı ile doğrudan alakalıdır. Kabak ve patlıcan diliminin kütle taşınım katsayısına kurutma havası hızı ve sıcaklığının etkisi araştırılmıştır. Ürün nem içeriğinin zamana bağlı bir süreçte her noktada aynı olduğu kabulüne dayanarak [23];

$$
V \frac{d M}{d t}=-h_{m} A\left(M_{i}-M_{e}\right)
$$

(6) numaralı denklem düzenlenirse;

$$
M R=\frac{M-M_{e}}{M_{i}-M_{e}}=\exp \left(-\frac{h_{m} A}{V} t\right)
$$

elde edilir. Dikdörtgen şekilli ürünlerde $V / A$ değeri yarı kalınlık olarak alınmıştır [23]. (7) numaralı denkleme SigmaPlot programında regresyon analizi uygulanarak $\mathrm{h}_{\mathrm{m}}$ değeri belirlenmiştir.

\section{BULGULAR VE TARTIŞMA}

Kurutma havası hızı ve sıcaklığının dilim şeklinde kesilen kabak ve patlıcanın kuruma davranışına etkisi deneysel olarak araştırılmıştır. Ayrıca, kabak ve patlıcan dilimlerinin difüzyon ve kütle taşınım katsayılarına hızın ve sıcaklığın olan etkisi de belirlenmiştir. Şekil 2'de kabağın kuruma süresine kurutma havası hızı ve sıcaklığının etkisi gösterilmiştir. Sabit sıcaklıkta tutulan $\left(50^{\circ} \mathrm{C}\right)$ kurutma havas 1 hizının artmasiyla kuruma süresinin azaladığ havası hızının artması dilim şeklinde kesilen kabak yüzeyi ile ortam havası arasında olan ısı ve kütle taşınımını da artırmaktadır. Isı ve kütle taşınım katsayılarının artması kurutma süresinin azalmasına 
sebep olmaktadır. Hizın $0.5 \mathrm{~m} / \mathrm{s}$ 'den $1.5 \mathrm{~m} / \mathrm{s}$ 'ye yükseltilmesiyle kurutma süresinin yaklaşı $\% 30$ oranında azaldığı tespit edilmiştir.

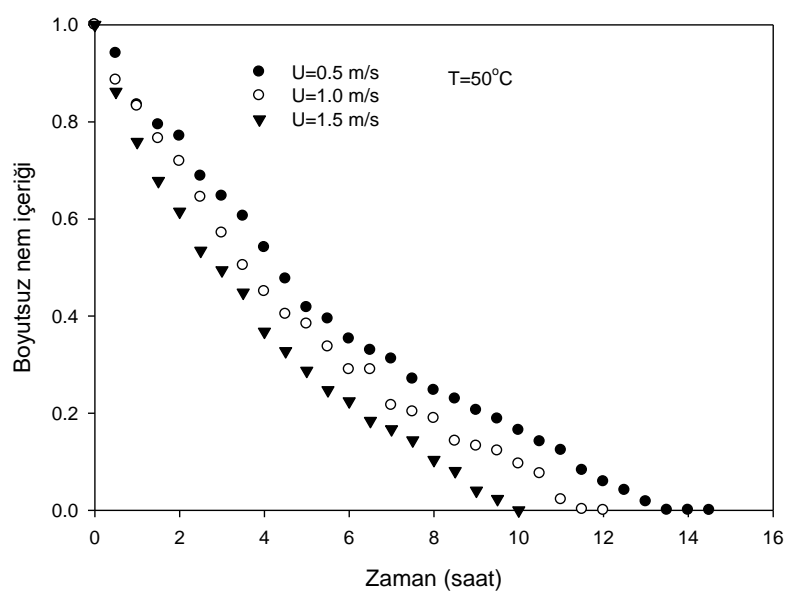

(a)

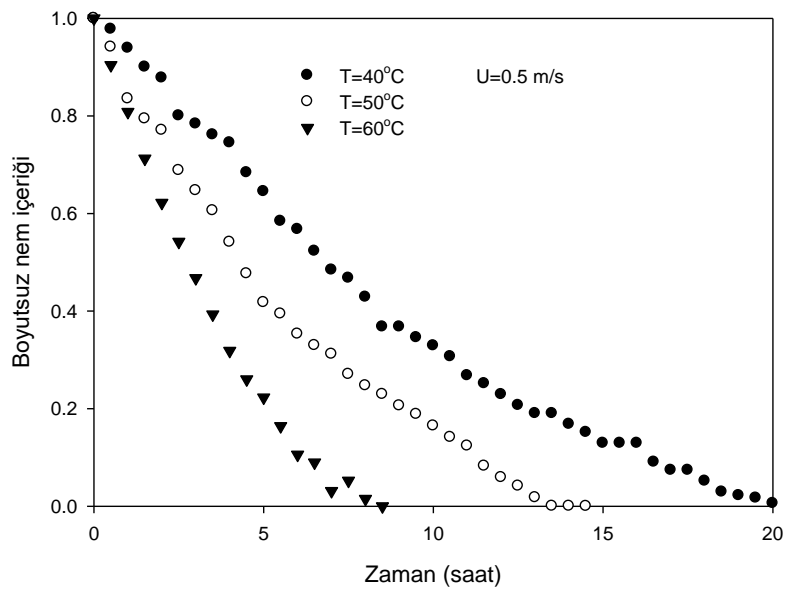

(b)

Şekil 2. Kabak dilimlerinin kurutulmasında kurutma havası hızı (a) ve sıcaklığının (b) etkisi

Şekil 2b'de kurutma havası sıcaklığının kabağın kuruma süresine etkisi gösterilmiştir. Difüzyon katsayısının sıcaklığa bağlı olduğu bilinmektedir. Sıcaklığın arrtması aynı zamanda ürün içinde difüzyon sürecini de hızlandırarak kuruma süresinin azalmasını sağlamaktadır. Kurutma havası hızının $0.5 \mathrm{~m} / \mathrm{s}$ 'de sabit tutulup sicaklığın $40{ }^{\circ} \mathrm{C}$ 'den $60^{\circ} \mathrm{C}$ 'ye yükseltilmesi ile toplam kurutma süresinin $\% 58.5$ oranında azaldığ edilmiştir.

Şekil 3'te patlicanın kuruma süresine kurutma havası hızı ve sıcaklığının etkisi gösterilmiştir. Sicaklığın sabit tutularak kurutma havası hızının 0.5 m/s'yeden $1.5 \mathrm{~m} / \mathrm{s}$ 'ye yükseltilmesiyle kurutma süresinde \%18 (Şekil 3a); kurutma havası sıcaklığının $40{ }^{\circ} \mathrm{C}$ 'den $60{ }^{\circ} C^{\prime}$ ye çıkartılmasıyla \%43 oranında azalmıştır (Şekil 3b).

Kurutma havası sicaklığı ve hızının kuruma süresine etkisi incelendiğinde, kurutma havası sıcaklığının daha etkin olduğu tespit edilmiştir. Kurutma havası sıcaklığının yükselmesiyle hem difüzyon katsayısı hem de ürün yüzeyi ile ortam havası arasında meydana gelen eş zamanlı 1s1 ve kütle transferi artmaktadır [6,24]. Hem difüzyon hem de taşınım etkilerinin artmasıyla kurutma süresinde önemli ölçüde azalma sağlanmaktadır.

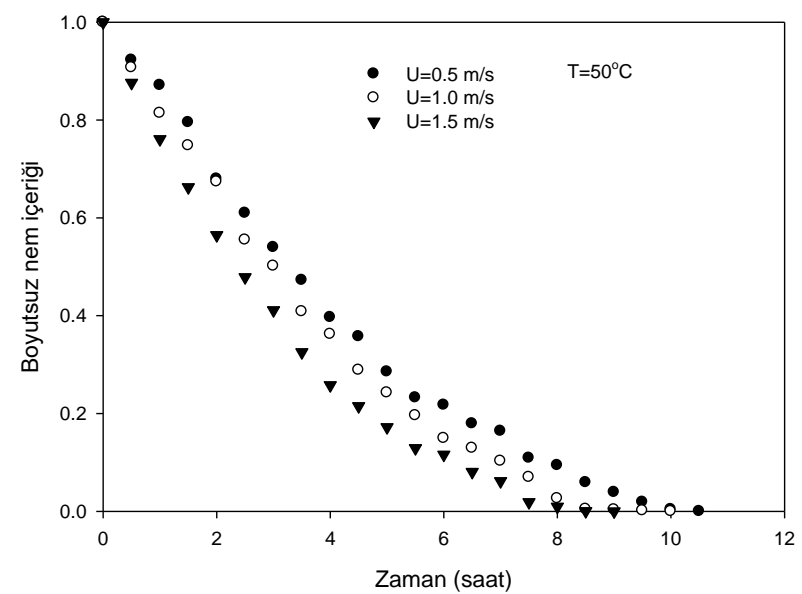

(a)

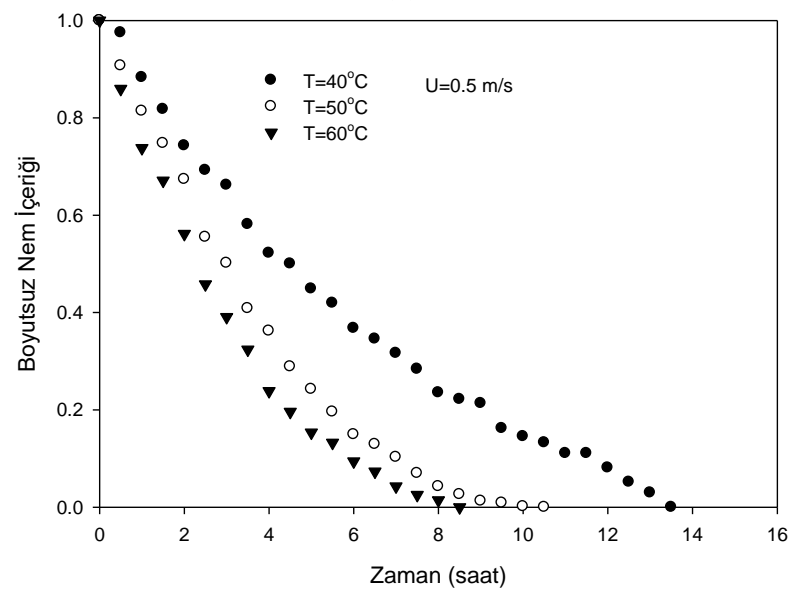

(b)

Şekil 3. Patlıcan dilimlerinin kurutulmasında kurutma havası hızı (a) ve sıcaklığının (b) etkisi

Kabak ve patlicanın kurutma sabitleri ve kurutma katsayıları literatürde yaygın olarak kullanılan ince tabakalı kurutma modellerinden Lewis, Henderson ve Pabis ve İki-terimli eksponasiyel modelleri kullanılarak tespit edilmiş ve Tablo 2 ve 3 'te verilmiştir. Modellerin uygulanabilirliğinde en önemli istatistiki pararmetrelerden olan korelasyon katsayısı $\left(R^{2}\right)$ ve tahmini standart sapmalar (SEE) her deney sonucuna göre Denklem (2) ve (3) kullanılarak belirlenmiş ve Tablo 2 ve Tablo 3 'te gösterilmiştir. Katsayıların doğruluğunu belirlemede en önemli parametre olan regresyon katsayısının $\mathrm{R}^{2}$, bütün modellerde 0.90'1n üstünde olduğu tespit edilmiştir. Regresyon katsayısının 0.90'dan büyük olması, elde edilen katsayıların kullanılabilirliğini göstermektedir [25,26]. Her iki ürün için yapılan deney sonuçlarının Henderson-Pabis ve İkiterimli eksponansiyel modellerine uygulanmasiyla elde edilen $\mathrm{R}^{2}$ değerlerinin Lewis modelinin uygulanmasıyla 
elde edilen $\mathrm{R}^{2}$ değerlerinden büyük olduğu tespit edilmiştir. $\mathrm{R}^{2}$ değerlerinin Henderson-Pabis ve İkiterimli eksponansiyel modellerinde 0.9685 ile 0.9888 arasında; Lewis modellerinde ise 0.9640 ile 0.9887 aralığında olduğu tespit edilmiştir.

Tablo 2. Kabak dilimlerinin kurutma sabit ve katsayılarının kurutma havası koşullarıyla değişimi

\begin{tabular}{|c|c|c|c|c|c|c|c|c|c|c|}
\hline \multicolumn{11}{|c|}{ Lewis } \\
\hline & & $\mathrm{U}=0.5 \mathrm{~m} / \mathrm{s}$ & $\mathrm{R}^{2}$ & SEE & $\mathrm{U}=1.0 \mathrm{~m} / \mathrm{s}$ & $\mathrm{R}^{2}$ & SEE & $\mathrm{U}=1.5 \mathrm{~m} / \mathrm{s}$ & $\mathrm{R}^{2}$ & SEE \\
\hline $\mathrm{T}=40^{\circ} \mathrm{C}$ & $\mathrm{k}(1 / \mathrm{h})$ & 0.1150 & 0.9640 & 0.0309 & 0.1361 & 0.9747 & 0.0473 & 0.1708 & 0.9643 & 0.0576 \\
\hline $\mathrm{T}=50^{\circ} \mathrm{C}$ & $\mathrm{k}(1 / \mathrm{h})$ & 0.1765 & 0.9774 & 0.0454 & 0.2079 & 0.9824 & 0.0395 & 0.2585 & 0.9887 & 0.0309 \\
\hline $\mathrm{T}=60^{\circ} \mathrm{C}$ & $\mathrm{k}(1 / \mathrm{h})$ & 0.2077 & 0.9685 & 0.0569 & 0.2527 & 0.9667 & 0.0588 & 0.2954 & 0.9679 & 0.0583 \\
\hline \multicolumn{11}{|c|}{ Henderson-Pabis } \\
\hline \multirow{2}{*}{$\mathrm{T}=40^{\circ} \mathrm{C}$} & $\mathrm{a}$ & 1.1074 & \multirow{2}{*}{0.9775} & \multirow{2}{*}{0.0472} & 1.0543 & \multirow{2}{*}{0.9786} & \multirow{2}{*}{0.0442} & 1.0565 & \multirow{2}{*}{0.9685} & \multirow{2}{*}{0.0552} \\
\hline & $\mathrm{k}(1 / \mathrm{h})$ & 0.1275 & & & 0.1435 & & & 0.1805 & & \\
\hline \multirow{2}{*}{$\mathrm{T}=50^{\circ} \mathrm{C}$} & $\mathrm{a}$ & 1.0568 & \multirow{2}{*}{0.9814} & \multirow{2}{*}{0.0419} & 1.0395 & \multirow{2}{*}{0.9845} & \multirow{2}{*}{0.0378} & 1.0078 & \multirow{2}{*}{0.9888} & \multirow{2}{*}{0.0315} \\
\hline & $\mathrm{k}(1 / \mathrm{h})$ & 0.1866 & & & 0.2163 & & & 0.2606 & & \\
\hline \multirow{2}{*}{$\mathrm{T}=60^{\circ} \mathrm{C}$} & $\mathrm{a}$ & 1.0997 & \multirow{2}{*}{0.9793} & \multirow{2}{*}{0.0470} & 1.0821 & \multirow{2}{*}{0.9745} & \multirow{2}{*}{0.0527} & 1.0782 & \multirow{2}{*}{0.9754} & \multirow{2}{*}{0.0526} \\
\hline & $\mathrm{k}(1 / \mathrm{h})$ & 0.2275 & & & 0.2725 & & & 0.3177 & & \\
\hline \multicolumn{11}{|c|}{ İki-terimli eksponansiyel } \\
\hline \multirow{4}{*}{$\mathrm{T}=40^{\circ} \mathrm{C}$} & $\mathrm{a}$ & 0.5867 & \multirow{4}{*}{0.9775} & \multirow{4}{*}{0.0484} & 0.0484 & \multirow{4}{*}{0.9786} & \multirow{4}{*}{0.0455} & 0.5495 & \multirow{4}{*}{0.9685} & \multirow{4}{*}{0.0573} \\
\hline & $\mathrm{k}_{0}(1 / \mathrm{h})$ & 0.1275 & & & 0.1435 & & & 0.1805 & & \\
\hline & $\mathrm{b}$ & 0.5207 & & & 0.5044 & & & 0.5070 & & \\
\hline & $\mathrm{k}_{1}(1 / \mathrm{h})$ & 0.1275 & & & 0.1435 & & & 0.1805 & & \\
\hline & $\mathrm{a}$ & 0.5465 & & & 0.5307 & & & 0.5083 & & \\
\hline $\mathrm{T}-50^{\circ} \mathrm{C}$ & $\mathrm{k}_{0}(1 / \mathrm{h})$ & 0.1866 & 09814 & 00435 & 0.2163 & 0.9845 & 00396 & 0.2606 & 09888 & 00333 \\
\hline $1=50^{\circ} \mathrm{C}$ & $\mathrm{b}$ & 0.5102 & 0.9814 & 0.0435 & 0.5088 & 0.9845 & 0.0396 & 0.4995 & 0.9888 & 0.0333 \\
\hline & $\mathrm{k}_{1}(1 / \mathrm{h})$ & 0.1866 & & & 0.2163 & & & 0.2606 & & \\
\hline & $\bar{a}$ & 0.5808 & & & 0.5732 & & & 0.5664 & & \\
\hline $\mathrm{T}-60^{\circ} \mathrm{C}$ & $\mathrm{k}_{0}(1 / \mathrm{h})$ & 0.2275 & 00703 & 00400 & 0.2725 & 0.0745 & 00556 & 0.3177 & 00754 & 00562 \\
\hline $1=60^{\circ} \mathrm{C}$ & $\mathrm{b}$ & 0.5189 & 0.9193 & 0.0490 & 0.5089 & 0.9145 & 0.0556 & 0.5117 & 0.9134 & 0.0002 \\
\hline & $\mathrm{k}_{1}(1 / \mathrm{h})$ & 0.2275 & & & 0.2725 & & & 0.3177 & & \\
\hline
\end{tabular}

Tablo 3. Patlıcan dilimlerinin kurutma sabit ve katsayılarının kurutma havası koșullarıyla değișimi

\begin{tabular}{|c|c|c|c|c|c|c|c|c|c|c|}
\hline \multicolumn{11}{|c|}{ Lewis } \\
\hline & & $\mathrm{U}=0.5 \mathrm{~m} / \mathrm{s}$ & $\mathrm{R}^{2}$ & SEE & $\mathrm{U}=1.0 \mathrm{~m} / \mathrm{s}$ & $\mathrm{R}^{2}$ & SEE & $\mathrm{U}=1.5 \mathrm{~m} / \mathrm{s}$ & $\mathrm{R}^{2}$ & SEE \\
\hline $\mathrm{T}=40^{\circ} \mathrm{C}$ & $\mathrm{k}(1 / \mathrm{h})$ & 0.1718 & 0.9804 & 0.0419 & 0.1990 & 0.9691 & 0.0547 & 0.2189 & 0.9848 & 0.0368 \\
\hline $\mathrm{T}=50^{\circ} \mathrm{C}$ & $\mathrm{k}(1 / \mathrm{h})$ & 0.2447 & 0.9679 & 0.0580 & 0.2776 & 0.9674 & 0.0590 & 0.3325 & 0.9833 & 0.0410 \\
\hline $\mathrm{T}=60^{\circ} \mathrm{C}$ & $\mathrm{k}(1 / \mathrm{h})$ & 0.2923 & 0.9720 & 0.0550 & 0.3419 & 0.9841 & 0.0397 & 0.4201 & 0.9867 & 0.0361 \\
\hline \multicolumn{11}{|c|}{ Henderson-Pabis } \\
\hline \multirow{2}{*}{$\mathrm{T}=40^{\circ} \mathrm{C}$} & $\mathrm{a}$ & 1.0691 & \multirow{2}{*}{0.9869} & \multirow{2}{*}{0.0350} & 1.0675 & \multirow{2}{*}{0.9747} & \multirow{2}{*}{0.0505} & 1.0363 & \multirow{2}{*}{0.9865} & \multirow{2}{*}{0.0354} \\
\hline & $\mathrm{k}(1 / \mathrm{h})$ & 0.1842 & & & 0.2123 & & & 0.2269 & & \\
\hline \multirow{2}{*}{$\mathrm{T}=50^{\circ} \mathrm{C}$} & $\mathrm{a}$ & 1.0936 & \multirow{2}{*}{0.9781} & \multirow{2}{*}{0.0491} & 1.0847 & \multirow{2}{*}{0.9753} & \multirow{2}{*}{0.0526} & 1.0552 & \multirow{2}{*}{0.9868} & \multirow{2}{*}{0.0375} \\
\hline & $\mathrm{k}(1 / \mathrm{h})$ & 0.2668 & & & 0.2996 & & & 0.3498 & & \\
\hline \multirow{2}{*}{$\mathrm{T}=60^{\circ} \mathrm{C}$} & $\mathrm{a}$ & 1.1032 & \multirow{2}{*}{0.9831} & \multirow{2}{*}{0.0438} & 1.0479 & \multirow{2}{*}{0.9869} & \multirow{2}{*}{0.0372} & 1.0198 & \multirow{2}{*}{0.9872} & \multirow{2}{*}{0.0366} \\
\hline & $\mathrm{k}(1 / \mathrm{h})$ & 0.3206 & & & 0.3575 & & & 0.4280 & & \\
\hline \multicolumn{11}{|c|}{ İki-terimli eksponansiyel } \\
\hline \multirow{4}{*}{$\mathrm{T}=40^{\circ} \mathrm{C}$} & $\mathrm{a}$ & 0.5571 & \multirow{4}{*}{0.9869} & \multirow{4}{*}{0.0364} & 0.5582 & \multirow{4}{*}{0.9747} & \multirow{4}{*}{0.0527} & 0.5326 & \multirow{4}{*}{0.9865} & \multirow{4}{*}{0.0371} \\
\hline & $\mathrm{k}_{0}(1 / \mathrm{h})$ & 0.1842 & & & 0.2123 & & & 0.2269 & & \\
\hline & $\mathrm{b}$ & 0.5120 & & & 0.5093 & & & 0.5036 & & \\
\hline & $\mathrm{k}_{1}(1 / \mathrm{h})$ & 0.1842 & & & 0.2123 & & & 0.2269 & & \\
\hline & $\mathrm{a}$ & 0.5775 & & & 0.5735 & & & 0.5482 & & \\
\hline $\mathrm{T}=50^{\circ} \mathrm{C}$ & $\mathrm{k}_{0}(1 / \mathrm{h})$ & 0.2668 & 0.9781 & 0.0518 & 0.2996 & 0.9753 & 0.0557 & 0.3498 & 0.9868 & 0.0399 \\
\hline & $\mathrm{b}$ & 0.5160 & 0.9101 & 0.0510 & 0.5112 & 0.9135 & - & 0.5070 & 0.9000 & \\
\hline & $\mathrm{k}_{1}(1 / \mathrm{h})$ & 0.2668 & & & 0.2996 & & & 0.3498 & & \\
\hline & $\mathrm{a}$ & 0.5839 & & & 0.5423 & & & 0.5223 & & \\
\hline $\mathrm{T}-60^{\circ} \mathrm{C}$ & $\mathrm{k}_{0}(1 / \mathrm{h})$ & 0.3206 & 09831 & 0.0463 & 0.3575 & 09869 & 00398 & 0.4280 & 09872 & 00396 \\
\hline $1=00 \mathrm{C}$ & $\mathrm{b}$ & 0.5193 & 0.9031 & 0.0403 & 0.5056 & 0.9009 & 0.0590 & 0.4975 & $0.90 / 2$ & 0.0390 \\
\hline & $\mathrm{k}_{1}(1 / \mathrm{h})$ & 0.3206 & & & 0.3575 & & & 0.4280 & & \\
\hline
\end{tabular}


Tablo 2 ve 3 incelendiğinde, elde edilen istatistiki parametreler 1 şığında $40-60{ }^{\circ} \mathrm{C}$ sıcaklıkları ve 0.5-1.5 $\mathrm{m} / \mathrm{s}$ hız değerleri arasında Henderson-Pabis ve İkiterimli Eksponansiyel modellerin kabağın ve patlıcanın kuruma davranışını belirlemede oldukça iyi sonuçlar verdiği söylenebilir. Ayrıca bütün kurutma modellerinde önemli bir parametre olan kurutma sabitlerinin (k) hız ve sicaklıkla arttığı görülmüştür. Şekil 4 ve 5 'te, deneysel olarak elde edilen boyutsuz nem içeriği ile model sonuçları karşılaştırılmıştır. Şekillerden görüldüğü gibi her iki modelden elde edilen sonuçlar ve deneysel sonuçlar oldukça uyumludur. Benzer sonuçlara literatürde farklı gıda ürünleri için de rastlanmıştır $[27,28]$.

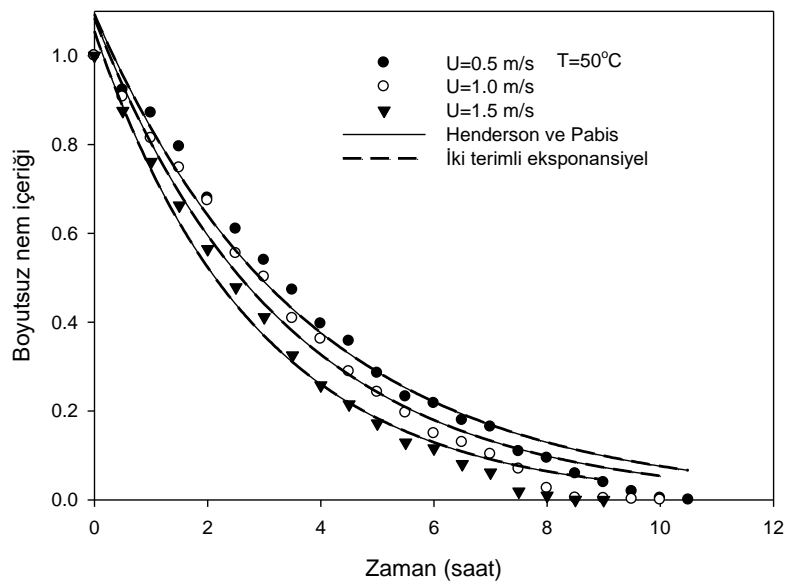

Şekil 4. Patlıcan dilimlerinin deneysel ve model sonuçlarının sabit sıcaklık için karşılaştırılması

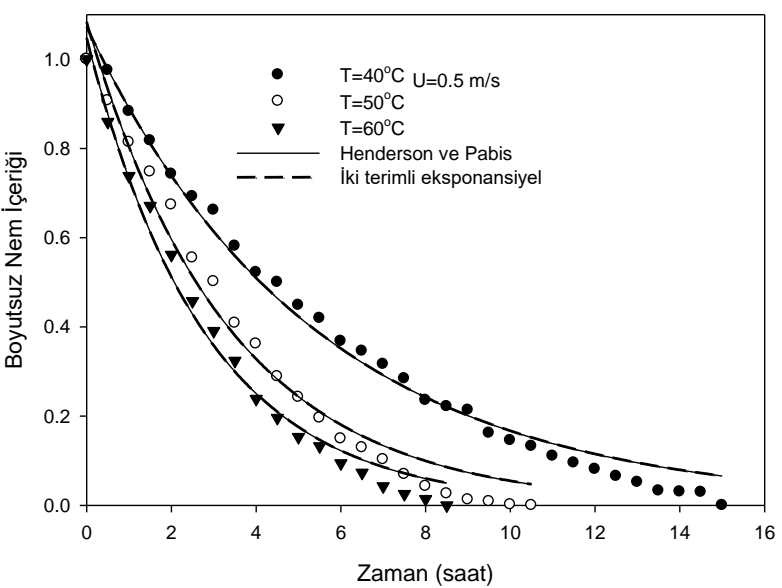

Şekil 5. Patlıcan dilimlerinin deneysel ve model sonuçlarının sabit hız için karşılaştırılması

(4) ve (7) numaralı denklemlere regresyon analizi uygulanarak hız ve sıcaklığın değişimine göre difüzyon

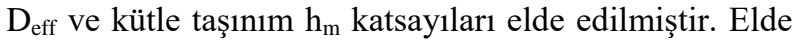
edilen sonuçlar Tablo 4 ve Tablo 5'te gösterilmiştir. Hızın ve sıcaklığın artmasıyla eş zamanlı ısı ve kütle transferi arttığından kurutma hızlanmış ve buna bağlı olarak kütle taşınım $h_{m}$ ve difüzyon katsayıları $D_{\text {eff }}$ 'in de arttığı görülmüştür. Difüzyon katsayısı için elde edilen bu değerlerin, literatürde gida ürünleri için belirlenen $10^{-8}$ ile $10^{-12} \mathrm{~m}^{2} / \mathrm{s}$ aralığında olduğu tespit edilmiştir [29].

Tablo 4. Kabak dilimlerinin difüzyon ve kütle tașınım katsayılarının kurutma havası koșullarıyla değișimi

\begin{tabular}{|l|c|c|c|c|c|c|c|}
\hline \multirow{2}{*}{$\mathrm{T}=40^{\circ} \mathrm{C}$} & $\mathrm{U}=0.5 \mathrm{~m} / \mathrm{s}$ & $\mathrm{R}^{2}$ & $\mathrm{U}=1.0 \mathrm{~m} / \mathrm{s}$ & $\mathrm{R}^{2}$ & $\mathrm{U}=1.5 \mathrm{~m} / \mathrm{s}$ & $\mathrm{R}^{2}$ \\
\cline { 2 - 8 } & $\mathrm{h}_{\mathrm{m}}(\mathrm{m} / \mathrm{s}) \times 10^{7}$ & 3.1944 & 0.9640 & 3.7806 & 0.9747 & 4.7444 & 0.9643 \\
\hline \multirow{2}{*}{$\mathrm{T}=50^{\circ} \mathrm{C}$} & $\mathrm{D}_{\text {eff }}\left(\mathrm{m}^{2} / \mathrm{s}\right) \times 10^{10}$ & 3.6489 & 0.9261 & 4.2339 & 0.9312 & 5.1572 & 0.9187 \\
\cline { 2 - 8 } & $\mathrm{h}_{\mathrm{m}}(\mathrm{m} / \mathrm{s}) \times 10^{7}$ & 4.9028 & 0.9774 & 5.7751 & 0.9824 & 7.1806 & 0.9887 \\
\cline { 2 - 8 } $\mathrm{T}=60^{\circ} \mathrm{C}$ & $\mathrm{D}_{\text {eff }}\left(\mathrm{m}^{2} / \mathrm{s}\right) \times 10^{10}$ & 5.1847 & 0.9305 & 5.8467 & 0.9539 & 7.4119 & 0.9704 \\
\cline { 2 - 8 } & $\mathrm{h}_{\mathrm{m}}(\mathrm{m} / \mathrm{s}) \times 10^{7}$ & 5.7694 & 0.9685 & 7.0194 & 0.9667 & 8.2056 & 0.9679 \\
\cline { 2 - 8 } & $\mathrm{D}_{\text {eff }}\left(\mathrm{m}^{2} / \mathrm{s}\right) \times 10^{10}$ & 6.4983 & 0.9847 & 7.5578 & 0.9426 & 9.0758 & 0.9513 \\
\hline
\end{tabular}

Tablo 5. Patlıcan dilimlerinin difüzyon ve kütle taşınım katsayılarının kurutma havası koşullarıyla değişimi

\begin{tabular}{|l|c|c|c|c|c|c|c|}
\hline & & $\mathrm{U}=0.5 \mathrm{~m} / \mathrm{s}$ & $\mathrm{R}^{2}$ & $\mathrm{U}=1.0 \mathrm{~m} / \mathrm{s}$ & $\mathrm{R}^{2}$ & $\mathrm{U}=1.5 \mathrm{~m} / \mathrm{s}$ & $\mathrm{R}^{2}$ \\
\hline \multirow{2}{*}{$\mathrm{T}=40^{\circ} \mathrm{C}$} & $\mathrm{h}_{\mathrm{m}}(\mathrm{m} / \mathrm{s}) \times 10^{7}$ & 4.7722 & 0.9860 & 5.5278 & 0.9841 & 6.0806 & 0.9823 \\
\cline { 2 - 8 } & $\mathrm{D}_{\text {eff }}\left(\mathrm{m}^{2} / \mathrm{s}\right) \times 10^{10}$ & 4.6672 & 0.9311 & 6.0092 & 0.9782 & 6.3386 & 0.9745 \\
\hline \multirow{2}{*}{$\mathrm{T}=50^{\circ} \mathrm{C}$} & $\mathrm{h}_{\mathrm{m}}(\mathrm{m} / \mathrm{s}) \times 10^{7}$ & 6.7972 & 0.9871 & 7.7111 & 0.9984 & 9.2361 & 0.9897 \\
\cline { 2 - 8 } & $\mathrm{D}_{\text {eff }}\left(\mathrm{m}^{2} / \mathrm{s}\right) \times 10^{10}$ & 7.7258 & 0.9445 & 8.2450 & 0.9832 & 9.9064 & 0.9674 \\
\hline \multirow{2}{*}{$\mathrm{T}=60^{\circ} \mathrm{C}$} & $\mathrm{h}_{\mathrm{m}}(\mathrm{m} / \mathrm{s}) \times 10^{7}$ & 8.1194 & 0.9955 & 9.4972 & 0.9967 & 11.6692 & 0.9729 \\
\cline { 2 - 8 } & $\mathrm{D}_{\text {eff }}\left(\mathrm{m}^{2} / \mathrm{s}\right) \times 10^{10}$ & 9.1378 & 0.9657 & 10.2336 & 0.9826 & 14.0436 & 0.9653 \\
\hline
\end{tabular}

\section{SONUÇLAR}

$\mathrm{Bu}$ çalışmada kurutma havası hızı ve sıcaklığının kabak ve patlıcan dilimlerinin kuruma davranışı ile difüzyon ve kütle transfer parametrelerine etkisi deneysel olarak araştırılmış ve aşağıdaki sonuçlara ulaşılmıştır;
1. Kurutma havası hızı ve sicaklı̆̆ının artmasıyla kurutma süresi azalmıştır.

2. Kurutma havası hızı ve sicaklığının artmasıyla difüzyon ve kütle taşınım katsayılarının arttığı belirlenmiştir. 
3. Deneysel veriler üç farklı kurutma modeline yerleştirilmiş ve Henderson-Pabis ile İki-terimli Eksponansiyel modellerinin uygun sonuçlar verdiği tespit edilmiştir.

\section{TEŞEKKÜR}

Bu çalışma; KSÜ Rektörlüğü Bilimsel Araştırma Projeleri Birimince 2013/3-38M nolu proje ile desteklenmiştir.

\section{KAYNAKLAR}

[1]. Akkuş, M., (2015), "Yarı Kurak İklim Koşullarında, Farklı Su Seviyelerinde Patlıcanın (Solanum Melongena L.) Sulama Programlarının Belirlenmesi ve Verim Bileşenlerine Etkisi”, Harran Üniversitesi, Yüksek Lisans Tezi, s87.

[2]. Keskin, A., (2014), “Isparta'da Yetiştirilen Kabak (Cucurbita Pepo)'ta Hiyar Mozayik Virüsü (Cucumber Mosaic Virus, Cmv)'nün Biyolojik, Serolojik ve Moleküler Yöntemlerle Araştırılması", Süleyman Demirel Üniversitesi, Yüksek Lisans Tezi, s66.

[3]. Karim, M.A., Hawlader, M.N.A., (2005), "Mathematical Modeling and Experimental Investigation of Tropical Fruits Drying", In. J. Heat Mass Tran. 48: 4914-4925.

[4]. Doymaz, İ., (1998), “Üzüm ve Kahramanmaraş Biberinin Kuruma Karakteristiklerinin İncelenmesi", Doktora Tezi, Y.T. Ü., FenBlimleri Enstitüsü, İstanbul.

[5]. Hussain, M.M., (2001), "Investigation of Heat and Moisture Transfer During Solids Drying", Yüksek Lisans Tezi, King Fahd University of Petroleum and Minerals, Dhahran, Suudi Arabia.

[6]. Kaya, A., Aydın, O., Demirtas, C., (2007), "Drying Kinetics of Red Delicious Apple", Biosyst. Eng., 96(4), 517-524.

[7]. Kouchakzadeh, A., Shafeei, S., (2010), "Modeling of Microwave-Convective Drying of Pistachios", Energ. Convers. Manage., 51, 20122015.

[8]. Doymaz, I., Gol, E., (2011), “Convective Drying Characteristics of Eggplant Slices", J. Food Process. Eng., 34, 1234-1252.

[9]. Doymaz, I., (2013), "Experimental Study on Drying of Pear Slices in A Convective Dryer", Int. J. Food Sci. Tech., 48, 1909-1915.

[10]. Ortiz, A.L., Ramirez, J.R., Lagunas, L.L.M., (2013), "Effects of Drying Air Temperature on The Structural Properties of Garlic Evaluated
During Drying”, Int. J. Food Prop., 16, 15161529.

[11]. Purkayastha, M.D., Nath, A., Deka, B.C., Mahanta, C.L., (2013), "Thin Layer Drying of Tomato Slices", J. Food Sci. Tech., 50(4), 642653.

[12]. An, K., Zhaob, D., Wangb, Z., Wua, J., Xua, Y., Xiaoa, G., (2016), “Comparison Of Different Drying Methods On Chinese Ginger (Zingiber Officinale Roscoe): Changes in Volatiles, Chemical Profile, Antioxidant Properties and Microstructure", Food Chemistry, 197, 12921300.

[13]. Tao, Y., Wanga, P., Wanga, Y., Kadamb, S.U., Hana, Y., Wanga, J., Zhouc, J., (2016), "Power Ultrasound as A Pretreatment to Convective Drying of Mulberry (Morus Alba L.) Leaves: Impact on Drying Kinetics and Selected Quality Properties", Ultrasonics Sonochemistry, 31, 310318.

[14]. Rahman, S.N.F.S.A., Wahida, R., Rahman, N.A., (2015), "Drying Kinetics of Nephelium Lappaceum (Rambutan) in A Drying Oven", Procedia - Social and Behavioral Sciences, 195, 2734-2741.

[15]. Adiletta, G., Russo, P., Senadeera, W., Di Matteo, M., (2016), "Drying Characteristics and Quality of Grape Under Physical Pretreatment", Journal Of Food Engineerıng, 172, 9-18.

[16]. Khawas, P., Dash, K.K., Das, A.J., Deka, S.C., (2015), "Drying Characteristics and Assessment of Physicochemical and Microstructural Properties of Dried Culinary Banana Slices", International Journal Of Food Engineering, 11(5), 667-678.

[17]. Lewis, W.K., (1921), "The Rate of Drying of Solid Materials", J. Indian Eng. Chem., 13(5): 427-432.

[18]. Henderson, S.M., Pabis, S., (1961), "Grain Drying Theory, II. Temperature Effects on Drying Coefficients", J. Agr. Eng. Res., 6: 169174.

[19]. Sharaf-Eldeen, Y.I., Blaisdell, J.L., Hamdy, M.Y., (1980), "A Model for Ear Corn Drying", Trans. ASAE, 23: 1261-1271.

[20]. Doymaz, I., (2007), "The Kinetics of Forced Convective Air-Drying of Pumpkin Slices", J. Food Eng. 79: 243-248.

[21]. Saeed, I.E., (2010), "Solar Drying of Roselle (Hibiscus Sabdariffa L.) Part I: Mathematical Modelling, Drying Dxperiments, Effects of The 
Drying Conditions", Agric Eng Int: CIGR J. 12 (3-4): 54-59.

[22]. Crank, J., (1975), "The Mathematics of Diffusion", Oxford University Press, London.

[23]. Incropera, F.P., De Witt, D.P., (1990), "Fundamentals of Heat and Mass Transfer", John Wiley\&Sons, New York.

[24]. Kaya, A., Aydin, O., Demirtas, C, Akgün, M., (2007), "An Experimental Study on The Drying Kinetics of Quince", Desalination 212: 328-243.

[25]. Madamba, P.S., Driscoll, R.H., Buckle, K.A., (1996), "The Thin Layer Drying Characteristic of Garlic Slices”, J. Food Eng., 29, 75-97.

[26]. Erenturk, S., Gulaboglu, M.S., Gultekin, S., (2004), "The Thin-Layer Drying Characteristics of Rosehip", Biosyst. Eng., 89, 2, 159-166.

[27]. Doymaz, I., (2007), “Air-Drying Characteristics of Tomatoes", J. Food Eng. 78: 1291-1297.

[28]. Akpinar, E.K., Bicer, Y., (2004), "Modelling of The Drying of Eggplants in Thin-Layers", Int. J. Food Sci. Techol. 39: 1-9.

[29]. Doymaz, I., (2012), "Evaluation of Some ThinLayer Drying Models of Persimmon Slices (Diospyros kaki L.)", Energ, Convers Manage. 56: 199-205. 